\title{
Ética para el desarrollo tecnológico \\ EN LA SOCIEDAD DEL. CONOCIMIENTO
}

\author{
León Olivé MoretT ${ }^{1}$
}

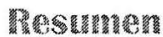

El concepto de "sociedad del conocimiento" ha venido utilizándose de manera cada vez más generalizada, aunque con múltiples significados. Este artículo reflexiona sobre las trasformaciones requeridas en la sociedad iberoamericana, para hacer tránsito en una sociedad del conocimiento, basado en la construcción de cultura técnica, tecnológica y científico-tecnológica, y su relación con las transformaciones requeridas en el estado y las actitudes ciudadanas. Estas transformaciones y mecanismos, permitirían construir sistemas sociales científico-tecnológicos, que incluyen los sistemas y los procesos donde se genera el conocimiento; los mecanismos para que dicho conocimiento sea socialmente aprovechado para las demandas de diferentes sectores; y la valoración ética y moral de las consecuencias que se derivan para los afectados y beneficiarios de este aprovechamiento.

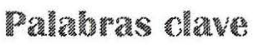

Ética, Técnica, Tecnología, Ciencia, Desarrollo, Sociedad del conocimiento.

1 Premio Universidad Nacional 2006. Área: Investigación en humanidades. Uno de los filósofos más notables de Iberoamérica. Egresado de la Universidad Nacional Autónoma de México (licenciatura en matemáticas, Facultad de Ciencias; maestría en filosofia, Facultad de Filosofia y Letras). Doctorado en filosofía, Universidad de Oxford, Inglaterra. Es Investigador de tiempo completo del Instituto de Investigaciones Filosóficas. 


\section{Abstract}

The concept "Knowledge society" is been used in generalized way, but with multiple meanings. This paper presents considers about the transformations required into the Iberoamerican society to become a knowledge society, based on the construction of technical, technological and techno-scientific culture, in addition to required transformations in the State and the attitude of the citizens. These transformations and mechanisms will allow to built scientific-technological social systems, which include the systems and processes where knowledge is generated; the mechanisms that allow knowledge be socially benefited to satisfy different social sectors demands; and ethical and moral evaluation of consequences derived for those people affected, both in a positive or negative way.

\section{Key words}

Ethics, Technique, Technology, Science, Development, Knowledge society. 


\section{LA SOCHEDAD DEL CONOCMMUNTO Y LOS SISTERAS CIENTIRCO TECNOLÓGICOS}

El concepto de "sociedad del conocimiento" ha venido utilizándose en tiempos recientes de manera cada vez más generalizada, aunque con múltiples significados y su uso no deja de ser controvertido. Pero no cabe duda de que hay fenómenos inéditos en la historia, surgidos a partir de transformaciones sociales ocurridas en las últimas décadas, que han resultado en un entorno con rasgos distintos a la sociedad industrial que se desarrolló hasta mediados del siglo XX. El concepto de sociedad del conocimiento se utiliza para referirse a tales rasgos. Entre ellos destaca el incremento espectacular del ritmo de creación, acumulación, distribución y aprovechamiento de la información y del conocimiento, así como el desarrollo de las tecnologías que lo han hecho posible, en particular las de la información y la comunicación que en buena medida han desplazado a las manufactureras. El concepto se refiere también a las transformaciones en las relaciones sociales, económicas y culturales debidas a las aplicaciones del conocimiento y al impacto de dichas tecnologías. Entre ellas se encuentra un desplazamiento de los conocimientos científico-tecnológicos hacia un lugar central como medios de producción, como insumos en los sistemas de innovación, cuyos resultados consisten en productos, procesos, formas de organización o servicios, que son aplicados para resolver problemas y para obtener beneficios para algún grupo humano. Por tanto, las personas altamente calificadas en cuanto a sus habilidades y conocimientos han adquirido un agregado valor económico, a grado tal que los procesos económicos tienden a la explotación de esas habilidades y conocimientos, mientras que la explotación de mano de obra barata y de recursos naturales ha pasado a segundo plano como generación de riqueza.

Pero no es que los recursos naturales y la mano de obra barata queden fuera de la esfera del interés económico. Por el contrario, lo que ha ocurrido en el contexto globalizado es que se han profundizado las desigualdades y las relaciones de dominación, y se ha 
dibujado un patrón en el que los países del norte asedian y despojan a los del sur de sus recursos naturales, mientras ellos se concentran en el desarrollo de nuevos conocimientos y tecnologías, cuyos beneficios rara vez alcanzan a los países y pueblos marginados. Por otra parte, como es de sobra conocido, los países pobres se ven obligados a exportar su mano de obra en condiciones indignas.

Otro de los grandes problemas que ahora enfrentamos es que la transformación de las formas de producción de conocimiento, las nuevas prácticas tecnológicas y tecnocientíficas, y las relaciones sociales, económicas, culturales y políticas en que éstas se han venido dando, han generado niveles de exclusión nunca antes vistos, así como nuevas formas de exclusión. En los países del primer mundo cada vez hay más gente desplazada del sistema económico formal -que no son sólo los inmigrantes-, y en el mundo entero hay cada vez más grupos sociales, y pueblos enteros que quedan excluidos de los beneficios de los nuevos sistemas tecnocientíficos y, peor aún, quedan excluidos de la posibilidad misma de generar conocimiento.

Esto es algo que ocurre palpablemente en las relaciones internacionales y muy especialmente en las ínter-culturales, y que afecta sensiblemente a los países del tercer mundo, particularmente a los pueblos tradicionales como prácticamente todos los pueblos indígenas de América Latina. Pero en cambio todos los excluidos del conocimiento y de sus beneficios comparten con el resto de los habitantes del planeta otra nueva forma de violencia: la carga de los riesgos y los daños. Esta es otra de las nuevas asimetrías: beneficios en las formas de vida para una minoría en el primer mundo, pero un primer mundo que ya no está sólo en el norte, sino que lo mismo está en América Latina que en la India o en China. Enormes ganancias económicas para un pequeño grupo de empresas, generalmente transnacionales, y exclusión de los beneficios para la enorme mayoría de los seres humanos.

Otro rasgo de la nueva sociedad que se está conformando consiste en una forma de producción del conocimiento donde los conceptos básicos son "auto-organización", "dispersión", "distribución" 
y "división" (cf. Hutchins 1996). En esta nueva forma ya no hay un lugar central de producción del conocimiento, sino que éste se genera de manera distribuida en muchas unidades dispersas, que físicamente pueden ser distantes, pero que a la vez se mantienen en contacto mediante redes de comunicación, de aquí el concepto de "sociedad red" como lo ha utilizado por ejemplo Manuel Castells (1999). El conocimiento producido por una unidad adquiere valor en la medida en que complementa y se suma al que se produce en los otros nodos de la red. El resultado es un nuevo conocimiento que emerge de la red misma y no es reductible a la mera suma de los conocimientos producidos en cada nodo. Para que esto sea posible se requiere cierto nivel de homogeneización cultural. Se encuentra aquí entonces una de las tendencias más fuertes que están empujando en la sociedad globalizada y del conocimiento: la de una estandarización que podría amenazar a las diversas identidades culturales del planeta.

Por otra parte, la forma distribuida de producción del conocimiento no significa una democratización del mismo, en el sentido de que sea público y accesible a todos, ni una disminución de la exclusión de millones de seres humanos de sus beneficios. Por el contrario, ni siquiera hay garantías de que quienes participan de una red se beneficien del conocimiento producido distribuidamente, o siquiera que sepan cuál es realmente el conocimiento que finalmente se produce.

En suma, entre los problemas que se plantean a los países latinoamericanos para transitar a la sociedad del conocimiento se encuentran los que surgen de la globalización, particularmente la tendencia hacia una homogenización cultural, por una parte; y por la otra, los que emanan de la necesidad de realizar transformaciones institucionales, legislativas y de políticas públicas, en educación, en economía, en la cultura y con respecto a la ciencia y la tecnología, así como cambios de actitud en los miembros de diferentes sectores sociales, que van desde las comunidades científicas y tecnológicas tradicionales, hasta los sectores empresariales y la clase política, pasando por los miembros de los diferentes pueblos 
que conviven en un país, y los ciudadanos en general, para poder establecer auténticos sistemas de innovación, tanto nacionales como regionales, y lograr insertarse a la vez en sistemas transnacionales de innovación, pero en condiciones de simetría con otros países.

Si por una sociedad justa entendemos una en la que se han establecido los mecanismos que garanticen las condiciones y la distribución de bienes de modo que se satisfagan las necesidades básicas de todos sus miembros, así como la posibilidad efectiva de que todos ellos puedan ejercer sus capacidades para llevar adelante sus planes de vida -siempre y cuando esos planes de vida sean compatibles con los de los otros miembros de la sociedad, es decir, que sean necesidades básicas legítimas ${ }^{2}$, entonces se hace necesaria una discusión de las políticas en ciencia y tecnología para que orienten el aprovechamiento de éstas para la satisfacción de esas necesidades básicas de los diferentes grupos sociales. Pero en los contextos de una genuina diversidad cultural, las necesidades básicas de los miembros de los diferentes pueblos y culturas no pueden ser definidas centralmente, sino que deben ser establecidas por los propios interesados.

En este contexto, una pregunta crucial es si las necesarias transformaciones institucionales, legislativas y de políticas públicas, en educación, en economía, en la cultura y con respecto a la ciencia y la tecnología, para establecer auténticos sistemas de innovación, son posibles únicamente mediante cambios voluntarios dentro de los países y los pueblos que quieran hacerlo, o si existen relaciones de poder y dominación que impiden las transformaciones aun cuando

2 Que sean compatibles con la realización de los planes de vida de los demás miembros de la sociedad quiere decir que su satisfacción no impida la satisfacción de las necesidades básicas de algún otro miembro de la sociedad (en el presente o en el futuro). Éstas son las necesidades básicas legítimas. Por consiguiente, el principio de justicia basado en la satisfacción de necesidades debería decir: "Una condición necesaria para que una sociedad sea justa es que establezca los mecanismos que garanticen las condiciones que permitan la satisfacción de las legítimas necesidades básicas de todos sus miembros" (véase Olivé 2004, cap. 7). 
algunos pueblos y países las deseen. Por ejemplo, ¿por qué con la excusa de vigilar la no proliferación de armas nucleares se impide el enriquecimiento de uranio para fines pacíficos en muchos países?

La brecha entre los países desarrollados científica y tecnológicamente y los que no los son ya es muy amplia. Pero en los que tienen poco desarrollo tecnocientífico, como los de América Latina, todavía existe un abismo mayor entre los sectores que participan de algunos de los beneficios de los sistemas de innovación, y aquellos completamente excluidos de estos procesos. Los países y los pueblos que continúen rezagados con respecto a su capacidad de innovación, es decir, de generar conocimiento y resultados que transformen a la propia sociedad y a su entorno, simplemente padecerán mayores injusticias en el contexto internacional, y muy probablemente incrementarán las internas.

Por consiguiente, una de las condiciones necesarias para el establecimiento de relaciones sociales justas es que las políticas a seguir en las próximas décadas por los Estados y por los organismos internacionales sean claros en permitir una mayor inversión en ciencia y tecnología, en la producción del conocimiento y en las formas de hacerlo verdaderamente disponible en la sociedad.

Pero el fortalecimiento y el desarrollo de la ciencia y la tecnología por sí solo no es suficiente, es necesario articular estos sistemas con el resto de la sociedad con el fin de que puedan atenderse los problemas tal y como son percibidos por los afectados, y no a partir de definiciones que de ellos se hagan en oficinas centrales de gobierno o de organismos internacionales. Esto requiere que se incremente sustancialmente la cultura científica y tecnológica de la población.

\section{LA CULTURA TECNCA, TECNOLOGICA, CIENÉFICA Y TENOCHENTIFCA}

¿Cómo entender y cómo aplicar los conceptos de "cultura científica" y "cultura tecnológica"? Para ofrecer una respuesta comencemos por recordar uno de los significados del concepto de "cultura" relevante para nuestros fines. 
Jesús Mosterín (1993) ha defendido la idea de cultura como "la información transmitida por aprendizaje social". A diferencia de la información que se transmite por medio de los genes -la herencia en sentido biológico, que es un fenómeno que pertenece a la "natura"-, hay información que se transmite mediante mecanismos de aprendizaje social, y en ese caso estamos ante la "cultura". El aprendizaje social puede lograrse por medio de la imitación, como ocurre en muchas especies animales, incluyendo la humana. Pero la información también puede transmitirse por medio de lenguajes verbales y no verbales, y puede codificarse en diferentes medios -tablillas de arcilla, papeles, libros, revistas, discos magnéticos, servidores electrónicos-. Su transmisión puede hacerse por diferentes vías: oralmente, en persona frente a frente, o por medios como el teléfono; por escrito, privadamente, por correo ordinario o por correo electrónico; o públicamente por medio de la prensa, de libros o de páginas de Internet. En todos los casos, la información necesita ser recuperada e interpretada ${ }^{3}$.

Actualmente se acepta ampliamente que los miembros de muchas especies animales utilizan herramientas y tienen sistemas de comunicación; es decir, transmiten información por medio del aprendizaje social, no únicamente por medio de los genes, y así hay cultura en muchas especies animales. Para autores como Mosterín lo que distingue a las sociedades humanas de las de otros animales es que la transmisión de la información se da también, y cada vez más, por medio de lenguajes proposicionales utilizando medios de apoyo artificiales: la escritura convencional en papel o en medios informáticos que se transmiten por Internet; la escritura por medio de lenguajes de computación, de lenguajes matemáticos, etc.

Sobre la base de este concepto de cultura, Miguel Ángel Quintanilla -quien ha hecho notables contribuciones a la filosofia de la tecnología (Quintanilla 2005)-, ha abordado específicamente el tema de la "cultura tecnológica". Este autor destaca ciertos elemen-

3 Para una discusión más amplia del concepto de cultura, véase Sobrevilla (ed.) 1998. 
tos que necesariamente están presentes en una cultura, y que en cada cultura específica tienen cierta organización: las representaciones, las reglas y normas de conducta, los valores, las formas de comunicación y las pautas de comportamiento aprendidas (no innatas) que caracterizan al grupo social en cuestión.

De acuerdo con el tipo de representación (creencias, teorías, modelos), de instrucciones, reglas y normas, de valores y de formas de comunicación (por medio del lenguaje proposicional, por medio de lenguajes no verbales, por ejemplo, corporales, de lenguajes visuales, pictóricos, etc.), es posible hablar de distintos tipos de culturas, por ejemplo la artística, la religiosa, la política, la empresarial, la económica o la científica. Pero a la vez las representaciones específicas, las creencias, los valores, las normas, variarán de un grupo social a otro, aunque se trate del mismo tipo de prácticas. Por ejemplo, dos grupos humanos diferentes pueden desarrollar prácticas religiosas que compartirán ciertas características que las vuelven religiosas y no, digamos, mercantiles -tener alguna idea de lo sagrado y actitudes con respecto a ello-, pero las creencias y los valores específicos de unas y otras pueden ser distintos.

Adelante regresaremos sobre el concepto de "práctica social" y su relación con la cultura. Por ahora comentaremos los conceptos de "técnica”, "artefacto" y "tecnología”, así como de "sistemas técnicos" y "tecnológicos", todos ellos necesarios para el análisis de los conceptos de "cultura científica" y de "cultura técnica".

Siguiendo a Quintanilla podemos entender las técnicas como sistemas de conocimientos, habilidades y reglas que sirven para resolver problemas. Las técnicas se inventan, se comunican, se aprenden y se aplican. Por ejemplo, podemos hablar de un grabado hecho con la técnica de punta seca, o de técnicas para resolver sistemas de ecuaciones.

Los artefactos son objetos que suelen ser el resultado de las transformaciones de otros objetos concretos mediante la operación de un sistema técnico (concepto que se elucida a continuación). Los artefactos se producen, se fabrican, se usan y se intercambian. Rara vez un ser humano deja de tener artefactos en su entorno: televi- 
sores, teléfonos, autobuses, ordenadores, aviones, pero pueden ser palos para cazar, y pieles de animales para protegerse del frío.

$\mathrm{Ni}$ las técnicas ni los artefactos existen al margen de las personas que las aplican o los usan con determinadas intenciones. Una piedra bruta no ha sido fabricada por nadie, no es un artefacto, pero puede ser usada como medio para pulir otra piedra, para romper una nuez o una cabeza. Cuando alguien la usa intencionalmente para transformar un objeto concreto y producir un artefacto, entonces ha creado un sistema técnico.

Un sistema técnico consta de agentes intencionales que persiguen fines determinados y de objetos que los agentes usan para transformar otros objetos. El resultado de la operación de un sistema técnico es un objeto que ha sido transformado intencionalmente: es un artefacto.

$\mathrm{Al}$ plantearse fines los agentes intencionales lo hacen contra un trasfondo de representaciones (creencias, teorías) y de valores. Alguien puede querer pulir una piedra porque cree que le servirá para cortar frutos. La piedra pulida es algo que el agente intencional considera valiosa. Los sistemas técnicos, entonces, también involucran creencias y valores.

Hoy en día los sistemas técnicos pueden ser muy complejos. Pensemos tan sólo en una planta núcleo-eléctrica. Además de complejos de acciones, involucran conocimientos científicos. Siguiendo la distinción de Quintanilla, llamaremos "tecnológicos" a los sistemas técnicos que involucran conocimientos de base científica y que se usan para "describir, explicar, diseñar, y aplicar soluciones técnicas a problemas prácticos de forma sistemática y racional" (Quintanilla y Aibar, 2002, 16). Desde este punto de vista los sistemas tecnológicos son, pues, una subclase de los sistemas técnicos.

Los sistemas técnicos son indispensables en toda sociedad humana. Los sistemas tecnológicos son propios de las sociedades industriales y de la sociedad del conocimiento. Pero en el siglo XX surgió todavía otro tipo de sistema técnico, más complejo que el tecnológico, que parece ahora ser característico de la sociedad del conocimiento: el sistema "tecnocientífico". 
Javier Echeverría (2003) se ha basado en la concepción básica de sistema técnico de Quintanilla para proponer una caracterización de los sistemas tecnocientíficos como sistemas de acciones intencionales que se guían por creencias, normas valores y reglas, que están vinculados a sistemas de información, que cuentan con una base científica y tecnológica, y que están ligados a sistemas e instituciones de investigación, pero también a otras organizaciones políticas, económicas, empresariales y muchas veces militares. Dichas acciones son llevadas a cabo por agentes, con ayuda de instrumentos y están intencionalmente orientadas a la transformación de otros sistemas con el fin de conseguir resultados que los agentes consideran valiosos, y que al aplicarse producen resultados que afectan positiva o negativamente a la sociedad y al ambiente.

Como los sistemas técnicos y tecnológicos, los tecnocientíficos están oxientados hacia la obtención de ciertos fines, para obtener los cuales se utilizan determinados medios. Un grupo de científicos y de empresarios, por ejemplo, pueden proponerse la producción de una nueva vacuna para comercializarla, o pueden plantearse la producción de órganos humanos con fines terapéuticos mediante técnicas de clonación. Los sistemas tecnocientíficos, como todos los sistemas técnicos, incluyen entonces agentes que tienen creencias y valores. Además incluyen a los objetos que los agentes usan con propósitos determinados (por ejemplo instrumentos utilizados para modificar genes y producir así organismos con determinadas características fenotípicas). Asimismo los sistemas tecnocientíficos contienen al menos un objeto concreto que es transformado (los genes que son modificados). El resultado de la operación del sistema tecnocientífico, el objeto que ha sido transformado intencionalmente por alguien, es un artefacto (por ejemplo un organismo genéticamente modificado, o un animal clonado como la oveja Dolly). Tanto los fines que se persiguen, los medios que se utilizan, como las intenciones bajo las cuales opera un sistema tecnocientífico y los resultados que de hecho se obtienen, son susceptibles de evaluación. Ésta puede ser realizada tanto por los agentes del mismo sistema, como por otros agentes desde un punto de vista externo al sistema 
tecnocientífico, por ejemplo instituciones académicas o grupos de ciudadanos. Estas evaluaciones son de primera importancia, y como parte del desarrollo de la cultura científico-tecnológica debería promoverse que cada vez más amplios sectores de la sociedad se involucren y estén debidamente preparados para hacerlas.

Los sistemas tecnocientíficos, como los científicos, buscan describir, explicar o predecir lo que sucede, pero no se limitan a ello, también tienen, como la tecnología, el propósito central de intervenir en partes del mundo natural y social y de transformarlas. Aunque las tecnociencias han tenido un crecimiento espectacular en las tres últimas décadas, y han desplazado en importancia económica y social a las ciencias y a las tecnologías tradicionales, éstas no han sido eliminadas. Lejos de ello, más bien asistimos hoy a una convivencia de sistemas técnicos, sistemas científicos, sistemas tecnológicos y sistemas tecnocientíficos.

Para lograr un desarrollo científico-tecnológico es necesario impulsar el crecimiento de la cultura científico-tecnológica, lo cual a la vez significa organizar a la sociedad para que todos los grupos, pueblos y culturas, aprovechen adecuadamente el conocimiento, y puedan promover y beneficiarse de las nuevas formas de producir y aplicar el conocimiento, particularmente mediante los sistemas tecnológicos y científico-tecnológicos. Pero no debería perderse de vista que esto tendría que hacerse dentro de marcos de de justicia social y de respeto a la diversidad cultural.

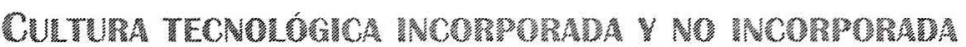

Quintanilla señala que la expresión cultura técnica tiene al menos dos acepciones: por un lado, la del conjunto de técnicas de que dispone un grupo social, en el sentido de habilidades, reglas y conocimientos prácticos para obtener ciertos fines y para transformar objetos -por ejemplo técnicas de agricultura-, y por el otro, la del conjunto de representaciones, reglas, normas y valores relacionados con las técnicas - por ejemplo, ideas (correctas o no) sobre la bondad o maldad de la biotecnología. 
Es posible extender esta idea para los casos de cultura científica y de cultura tecnocientífica, es decir, como los conjuntos de representaciones (creencias, conocimientos, teorías, modelos), de normas, reglas, valores y pautas de conducta que tienen los agentes de los sistemas técnicos, científicos o tecnocientíficos, y que son indispensables para que funcione el sistema, por un lado; y los conjuntos de esos mismos elementos que son relevantes para la comprensión, la evaluación, y las posibilidades de aprovechamiento de la técnica, de la tecnología, de la ciencia y de la tecnociencia por parte de una sociedad, de un pueblo o de ciertos grupos sociales. Es decir, se trata del conjunto de elementos que conforman las actitudes sobre la ciencia y la tecnología.

Cuando pensamos entonces en la cultura técnica, en la cultura tecnológica o en la cultura científico-tecnológica de un país, deberíamos considerar esa doble dimensión. Pero es claro que las representaciones y las evaluaciones que tengan y hagan los diferentes grupos sociales sobre los sistemas técnicos, tecnológicos y científico-tecnológicos pueden variar ampliamente, lo cual se agudiza en los países culturalmente diversos. Esto plantea problemas sobre los que es necesario reflexionar a fondo. Por ejemplo: ¿qué significa desarrollar la cultura tecnológica y tecnocientífica en el caso de los países de América Latina, y particularmente de sus pueblos indígenas que tienen culturas diferentes y se encuentran marginados educativa y económicamente?

Para profundizar sobre el problema conviene citar la distinción que propone Quintanilla entre la "cultura incorporada" a un sistema técnico y la "cultura no incorporada".

La cultura tecnológica incorporada a un sistema técnico está formada por el conjunto de creencias o conocimientos, hábitos y valores que los operadores de un sistema técnico necesitan tener para que éste funcione de forma adecuada. La cultura tecnológica de un grupo social (un país, una empresa, etc.) en sentido estricto o restringido se puede definir como el conjunto de todos los rasgos culturales incorporados a los sistemas técnicos de que dispone: incluye por lo tanto el nivel de formación 
y entrenamiento de sus miembros en el uso o diseño de esas tecnologías, pero también la asimilación de los objetivos de esas tecnologías como valores deseables, etc.

La cultura tecnológica no incorporada a sistemas técnicos está formada por el conjunto de rasgos culturales que se refieren o se relacionan con la tecnología, pero que no están incorporados a sistemas técnicos concretos, bien sea porque no son compatibles con las tecnologías disponibles, o porque no son necesarios para ellas, etc. Por ejemplo, un buen conductor de automóviles necesita determinados conocimientos sobre la mecánica del automóvil, un cierto nivel de entrenamiento en la práctica de conducir y una cierta interiorización de valores que representan las normas de tráfico (respetar la prioridad en los cruces, etc.). Todo esto constituye una parte de la cultura incorporada a la tecnología del automóvil de nuestros días. Pero además de eso el conductor puede tener determinadas creencias (acertadas o no) sobre el efecto contaminante de los motores de combustión interna, puede tener ciertas pautas de comportamiento en relación con el transporte individual y determinados valores referidos a la necesidad de preservar de la contaminación el centro histórico de las ciudades. Todos estos rasgos forman parte de una cultura tecnológica, en la medida en que afectan al uso, diseño y difusión de determinadas tecnologías, pero pueden no estar incorporados, por el momento, a ningún sistema técnico concreto (Quintanilla 2005, 277).

Puesto que los sistemas tecnocientíficos son una subclase de los sistemas técnicos, es posible aplicar esta idea para el caso de la "cultura tecnocientífica", que estaría constituida, por una parte, por los conjuntos de representaciones (creencias, conocimientos, teorías, modelos), de normas, reglas, valores y pautas de conducta que tienen los agentes de los sistemas tecnocientíficos, y que son indispensables para que funcione el sistema, por un lado; y por otra, la cultura tecnocientífica de una sociedad estaría formada por los conjuntos de esos mismos elementos que son relevantes para la comprensión, la evaluación, y las posibilidades de aprovechamiento de la tecnociencia por parte de una sociedad, de un pueblo o de ciertos grupos sociales. Es decir, se trata del conjunto 
de elementos que conforman las actitudes sobre los sistemas científico-tecnológicos y sus consecuencias.

Como señala Quintanilla, la distinción es relevante, por ejemplo, para comprender que si una empresa desea adoptar una nueva tecnología, es indispensable que su personal tenga la preparación técnica adecuada para operarla, so pena de fracaso. Pero también puede haber un fracaso debido, no a la falta de cultura tecnológica incorporada -pues los operarios pueden saber perfectamente cómo funciona la nueva tecnología-, sino precisamente a la no incorporada, por ejemplo, a que los operarios crean (con razón o sin ella) que los productos afectarán negativamente la salud humana o al ambiente, y tengan valores ecológicos que les induzcan a rechazar la tecnología en cuestión. Se trata, pues, de factores culturales que pueden afectar la adopción, el desarrollo y el éxito en la aplicación, uso y aprovechamiento de una cierta tecnología.

Pero igualmente puede ocurrir que aunque un cierto grupo social tenga la capacidad de incorporar el conocimiento necesario para operar un determinado sistema técnico, no considere deseables ni los fines que se persiguen con su operación, ni los medios para lograrlos, por lo cual rechace su uso. El destino de una tecnología, o más precisamente, de un sistema tecnológico en relación con un cierto grupo social depende en buena medida de la cultura tecnológica no incorporada de ese grupo.

\section{Prácticas COGNTIVAS, PRÁCTICAS CIENTIFICAS}

La idea de "cultura" (científica, tecnológica, tecnocientífica) que hemos comentado puede combinarse con otro concepto que si bien tiene una larga tradición en el pensamiento occidental, ha adquirido una singular relevancia en tiempos recientes: el concepto de "práctica".

Una práctica será entendida como un sistema dinámico que incluye al menos los siguientes elementos, los cuales se subrayan aquí para propósitos analíticos, pero que deben verse como íntimamente relacionados e interactuando entre sí: 
a) Un conjunto de agentes con capacidades y con propósitos comunes. Una práctica siempre incluye un colectivo de agentes que coordinadamente interactúan entre sí y con el medio. Por tanto, en las prácticas los agentes siempre se proponen tareas colectivas y coordinadas.

b) Un medio del cual forma parte la práctica, y en donde los agentes interactúan con otros objetos y otros agentes.

c) Un conjunto de objetos (incluyendo otros seres vivos) que forman también parte del medio.

d) Un conjunto de acciones (potenciales y realizadas) que están estructuradas. Las acciones involucran intenciones, propósitos, fines, proyectos, tareas, representaciones, creencias, valores, normas, reglas, juicios de valor y emociones (véase Schatzki 1996, y Schatzki, Knorr Cetina y Savigny (eds.) 2001). De este conjunto conviene destacar:

$d_{1}$ ) Un conjunto de representaciones del mundo (potenciales y efectivas), que guían las acciones de los agentes. Estas representaciones incluyen creencias (disposiciones a actuar de una cierta manera en el medio), y teorías (conjuntos de modelos de aspectos del medio).

$\mathrm{d}_{2}$ ) Un conjunto de supuestos básicos (principios), normas, reglas, instrucciones y valores, que guían a los agentes al realizar sus acciones y que son necesarios para evaluar sus propias representaciones y acciones, igual que las de otros agentes. Esta es la estructura axiológica de una práctica.

Sobre la noción de valor, siguiendo autores como Mario Bunge (y muchos otros) supondremos que no existen los valores en sí mismos, sino que lo que existe son cosas, objetos, acciones, situaciones, relaciones, animales y gente, que ciertos agentes consideran valiosas (cf. Bunge 1996, 141 y ss). De una manera más técnica, podemos seguir la propuesta de Javier Echeverría de considerar a los valores como funciones que se pueden aplicar sobre argumentos que pueden ser objetos, creencias, acciones, personas, sistemas, animales, artefactos, etc. (Echeverría 2002). Esto significa que los 
valores existen sólo cuando los agentes de una práctica valoran algo en circunstancias específicas. Los valores tienen significado sólo cuando los agentes (individuales o colectivos) realizan la acción de evaluar. De otro modo tenemos solo términos valorativos vacíos (belleza, elegancia, justicia, simplicidad, precisión, etc.). Pero en cambio, en situaciones específicas decimos que tal acción de una persona fue injusta con otra, o que determinada demostración matemática es simple y elegante, o que tal medición es sumamente imprecisa, etc. Pero no existe tal cosa como el valor "belleza", en abstracto, existen atardeceres hermosos, sinfonías bellas y mujeres preciosas.

Las prácticas cognitivas, pues, sólo pueden desarrollarse por grupos humanos y no por individuos aislados. La adecuación de una práctica no es una cosa de todo o nada, sino es un asunto gradual, que tiene que ver con la medida en que los agentes de la práctica logran los fines que se proponen. Diremos que un sistema axiológico es correcto, si la práctica a la que pertenece ese sistema es adecuada. Ambas características (adecuación y corrección), de las prácticas y de sus sistemas axiológicos, dependen tanto de las capacidades cognitivas y de acción de los agentes, como del medio dentro del cual deben llevar a cabo sus acciones y al cual necesariamente deben transformar. Como los medios son muy diversos, de ahí surge la amplia variedad de prácticas y, por tanto, de sistemas axiológicos correctos.

La tesis central que sugiero, entonces, es que la diversidad axiológica de las prácticas cognitivas es el resultado normal y esperable a partir de la naturaleza misma de las prácticas y del hecho que necesariamente se desarrollan en medios específicos que varian unos de los otros.

Por lo anterior, cuando se adoptan nuevas tecnologías, es indispensable tomar en cuenta las prácticas que serán afectadas por ellas, tanto como el entorno en que se desarrolla dicha práctica, que también sufrirá transformaciones. Los agentes miembros de la práctica en cuestión deberán evaluar los posibles cambios en su propia práctica y en su medio. Una de las tareas fundamentales 
para fortalecer y desarrollar la cultura científica y tecnológica consiste en preparar a los agentes de las prácticas afectadas para realizar críticamente tales evaluaciones.

En suma, al diseñar políticas para fomentar la cultura tecnológica es necesario tomar en cuenta los diferentes niveles de cultura incorporada que se requiere para la operación adecuada de un sistema técnico. No es posible progresar desde un punto de vista tecnológico, si no se ofrece a la gente la preparación adecuada para operar y en su caso para utilizar determinados sistemas técnicos. Pero tan importante como lo anterior, es que cada sistema técnico se utiliza en función de determinados fines, para obtener los cuales se usan ciertos medios. Es necesario también que desde el punto de vista de la cultura no incorporada se pueda hacer una evaluación crítica del sistema y de las consecuencias de su aplicación, tanto por quienes utilizarán los sistemas técnicos en cuestión como por quienes se verán afectados por su operación.

Potenciar el desarrollo tecnológico, entonces, no significa únicamente utilizar más tecnología; debe querer decir, sobre todo, desarrollar la cultura tecnológica, es decir, tener la capacidad de diseñar, desarrollar, utilizar, aprovechar y evaluar los sistemas técnicos apropiados para los fines que persiguen agentes concretos, de carne y hueso. Así, una sociedad es culta tecnológicamente si, por una parte, cuenta con grupos que tienen la cultura tecnológica incorporada pertinente para operar adecuadamente los sistemas tecnológicos que requiere, pero además, si la gente en general cuenta con la preparación para hacer evaluaciones de los sistemas tecnológicos y tecnocientíficos desde el punto de vista de la cultura no incorporada y si puede realizar tales evaluaciones de manera autónoma. Pero a todo esto hay que añadir que la cultura tecnológica debe incluir la capacidad para vigilar y controlar adecuadamente los riesgos que generan los sistemas técnicos, tecnológicos y científico-tecnológicos.

El fomento de la cultura científica y tecnológica no debe entenderse como adoctrinamiento, sino como el entrenamiento de los miembros de los diversos pueblos que les permita comprender 
el potencial de la ciencia y la tecnología para la resolución de ciertos problemas, pero sobre todo debe ser un entrenamiento para participar en las nuevas prácticas de producción de conocimiento, como prácticas transdisciplinarias, en donde concurren muy diversos puntos de vista para conformar nuevos marcos conceptuales y métodos para abordar y resolver problemas inéditos. Tales prácticas transdisciplinarias no existen en abstracto ni pueden conformarse de acuerdo con un único modelo. Se trata más bien que cada pueblo incorpore en su modo de vida prácticas y formas de abordar y resolver problemas que incluyen formas de producción de conocimiento como las que hoy en día conocemos como científicas y tecnocientíficas. Esto significa abrir el horizonte de posibilidades de acción de los miembros del pueblo, de una manera que respete su autonomía como individuos y como pueblos.

No hay que olvidar que la cultura tecnológica y la tecnocientífica forman parte de la cultura técnica, por lo que el objetivo debería ser el fortalecimiento de la cultura técnica en general. Esto significa que una sociedad es culta técnicamente, si además de la preparación para aprovechar y evaluar, en su caso, los sistemas tecnológicos y científico-tecnológicos, sus miembros están adecuadamente capacitados para desarrollar, aprovechar, evaluar y combinar con aquéllos otros sistemas técnicos, muchos de los cuales pueden ser productos culturales tradicionales, especialmente en el caso de pueblos con culturas ancestrales. Mayor cultura técnica tendrá una sociedad, mientras mayor sea su capacidad para aprovechar críticamente, y combinar, los beneficios de todos los tipos de sistemas técnicos, tecnológicos y científico-tecnológicos.

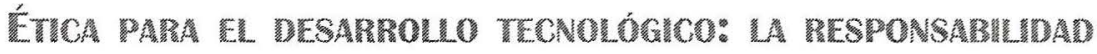 DE LOS CLENTÉrECOS Y LOS TRCNÓlOGOS}

Dentro del marco que hemos revisado hasta aquí, veamos ahora algunos de los desafíos éticos que plantea el desarrollo tecnológico. Comencemos por un examen de algunas de las responsabilidades de científicos y de tecnólogos. 
En el panorama mundial hoy, como nunca antes, la ciencia y la tecnología están en el centro de los enfrentamientos entre pueblos, naciones, Estados y otros grupos con intereses propios, como en la guerra de Irak, el conflicto palestino-israelí, la violencia y discriminación de los países del norte frente a los inmigrantes, las luchas terroristas o las batallas en torno al narcotráfico. ¿Se trata de problemas de los cuáles los únicos responsables son los políticos, o los militares, o los delincuentes, quienes toman decisiones a nivel económico, político, militar o policial? ¿No tienen ninguna responsabilidad al respecto los científicos y los tecnólogos? Y si la tienen, ¿cuál es, y de dónde surge?

La responsabilidad de los científicos hoy en día es doble. No porque tengan dos responsabilidades distintas, sino porque es una responsabilidad que se duplica en la medida en que desempeñan un papel social tanto como ciudadanos y como científicos, es decir, como ciudadanos científicos.

Esa responsabilidad se deriva de tener conocimientos que no son accesibles en toda su profundidad al ciudadano de la calle (y normalmente el acceso del ciudadano a esos conocimientos es apenas el de enterarse de ciertos nombres). Ese tipo de responsabilidades surgen dentro de los sistemas de ciencia y tecnología porque, en determinadas circunstancias, tener un cierto conocimiento y pertenecer a una determinada práctica científica, implica tener una responsabilidad ética y el deber de elegir entre cursos de acción posibles.

Para ver más claramente esto hagamos un experimento mental. Supongamos que dos biotecnólogos trabajan para una empresa donde se manipulan genes de semillas para la producción de fármacos, y que potencialmente los resultados de las investigaciones pueden conducir a productos eficientes para el tratamiento de enfermedades humanas, o a ciertas armas biológicas con base en microorganismos resistentes a antibióticos y vacunas. Supongamos además que alguna organización pacifista les pide que firmen un documento en el que se comprometen a no realizar trabajo alguno que pueda ser aplicado con fines bélicos. Uno de los dos biotec- 
nólogos firma el documento y el otro no, pero ambos continúan trabajando para la misma empresa. ¿Qué podemos decir sobre su responsabilidad?

Por mucho tiempo se ha mantenido una concepción sobre la ciencia y la tecnología según la cual éstas son neutrales desde el punto de vista de los valores y de la moral. Desde esa perspectiva, el uso que se dé a los conocimientos científicos y a los productos tecnológicos no es responsabilidad de los científicos, ni de los tecnólogos, más bien es un problema -y una responsabilidad-de quienes utilicen esos conocimientos y esos artefactos para obtener fines determinados. En todo caso, son esos objetivos, y los medios utilizados para lograrlos, los que sí podrían ser evaluados desde un punto de vista moral. Pero esos objetivos, concluye dicha posición, no los definen los científicos, sino los gobernantes, los políticos, los militares o los delincuentes organizados.

Bajo esta idea de la neutralidad valorativa de la ciencia y de la tecnología, en el ejemplo mencionado antes ninguno de los dos biotecnólogos tiene responsabilidad moral por el fin último al que se destine el resultado de su investigación. Así, tendría razón el biotecnólogo que se niega a firmar el documento, pues no puede comprometerse a que su trabajo "no sea utilizado" para algún fin bélico. En cambio, el que firma el documento se comporta ingenuamente, pues otros podrían beneficiarse del resultado de su trabajo y desviarlo hacia un uso bélico, sin responsabilidad alguna de su parte.

Pero existe otra manera de ver el problema. Según ese otro punto de vista, es necesario analizar todo el sistema del cual forman parte los dos biotecnólogos, como seres humanos, como ciudadanos y como científicos. Si el fin que se busca al diseñar y operar el sistema tecnocientífico en cuestión es la producción de un fármaco para tratar una enfermedad humana, en la medida en que ese objetivo no sea éticamente reprobable, los dos biotecnólogos realizan un trabajo aceptable. Por consiguiente, el que firma el documento se comporta correctamente desde un punto de vista ético. Pero con eso adquiere una responsabilidad mayor, 
pues por el hecho de firmar queda comprometido a participar en la vigilancia del destino del producto que él mismo contribuye a crear. El biotecnólogo que no firma elude la responsabilidad sobre las consecuencias de su trabajo.

Sobre cuestiones científicas y técnicas, quienes tienen el conocimiento más profundo son los científicos y los tecnólogos, aunque después otros sectores de la sociedad puedan tener acceso a él -por ejemplo cuando hay buenos mecanismos de comunicación de la ciencia- y entonces esos otros sectores también adquieren una responsabilidad. Pero antes de que otros sectores tengan ese conocimiento la responsabilidad no es exactamente la misma. Por eso, un deber de las comunidades científicas es comunicar a la sociedad con transparencia sus conocimientos, pero no sólo en cuanto a los contenidos, sino también sobre los riesgos de sus aplicaciones y sobre lo que ignoran al respecto. Es decir, por ejemplo, que es posible que haya consecuencias negativas que aún desconocen.

La responsabilidad de los científicos no se limita a establecer más allá de dudas razonables la existencia de relaciones causales entre fenómenos, o en todo caso encontrar formas de manipularlos. El problema de cómo y por qué actuar una vez que han producido cierto conocimiento -digamos sobre la naturaleza y el potencial infeccioso de cierto virus, y por consiguiente sobre la posibilidad de producir un arma biológica-, que es un problema ético y político, lo tiene que enfrentar el científico como científico, y no como si fuera un ciudadano o político divorciado de su papel de científico. Adquirir un conocimiento y tener una responsabilidad ética, en casos así, son dos caras de una misma moneda.

Pero es obvio que en la práctica ningún científico puede tener control sobre todas las aplicaciones que pueden llegar a hacerse de los conocimientos que genera. Además, un rasgo característico de los sistemas de producción de conocimiento actualmente es que nunca se podrán conocer todas las consecuencias de la aplicación de ese conocimiento o de sus desarrollos tecnológicos. ¿Hay alguna responsabilidad ante este tipo de situaciones? ¿Es posible hacer algo? 
En primer lugar, los expertos tienen el deber ante el público de informar transparentemente acerca de los límites de lo que saben con respecto a las posibles consecuencias de las aplicaciones de conocimientos específicos. En segundo lugar, los científicos y tecnólogos deberían colaborar en el establecimiento de mecanismos sociales de control y de vigilancia del uso del conocimiento científico y tecnológico, y de monitoreo de las consecuencias de sus aplicaciones, en donde los especialistas participen junto con representantes ciudadanos de otros sectores sociales. En el resto del trabajo abundaremos en las razones que sostienen este punto de vista. Por ahora comentemos una distinción entre moral y ética.

\section{Distinción ENTRE MORAL Y ÉTICA}

Por "moral" se entiende moral positiva, es decir, el conjunto de normas y valores morales de hecho aceptados por una comunidad para regular las relaciones entre sus miembros. Por ética se entiende el conjunto de valores y de normas racionalmente aceptados por comunidades con diferentes morales positivas, que les permiten una convivencia armoniosa y pacífica, y que incluso puede ser cooperativa. El respeto a la diferencia, así como la tolerancia, por ejemplo, son valores éticos fundamentales.

Bajo esta perspectiva, el problema central de la ética se entiende como la fundamentación de normas legítimas de convivencia para la acción y para la interacción entre seres humanos. La posibilidad de llegar a acuerdos sobre normas legítimas por parte de grupos con morales positivas distintas reside en que cada grupo encuentra razones para aceptarlas, aunque esas razones, por depender de morales diferentes, no sean las mismas. Es decir, cada grupo social puede tener razones distintas para aceptar una misma norma o un mismo valor; por ejemplo, el respeto a la dignidad humana.

En suma, la ética no debe ser entendida como la disciplina filosófica encargada de fundamentar un conjunto fijo y determinado de valores y de normas, sino como una parte multidimensional de muchas prácticas sociales. El objetivo de la ética, vista de este modo, es proponer y analizar críticamente el conjunto de valores 
y de normas mínimas a las que deberían llegar los grupos sociales involucrados en esas prácticas, junto con los que son afectados por ellas. Para comprender mejor esta idea, nos concentraremos en la bioética como un caso ejemplar, y haremos una comparación con la tarea central de la epistemología actualmente.

\section{LAS DIMENSIONES DESCRIPTIVAS Y PRESCRIPTINAS \\ DE LA EPSTEMOLOGIA Y DE LA BIOÉTCA}

Proponemos entender las tareas centrales de la epistemología y de la ética como facetas distintas de un mismo proyecto, a saber, el análisis y la crítica constructiva de la dimensión y de la estructura axiológica de las prácticas humanas. Un tipo de prácticas que se encuentran en el centro del interés para la epistemología y para la ética en las sociedades contemporáneas son las científicotecnológicas.

Para nuestros fines entenderemos a la epistemología como la disciplina que analiza críticamente las prácticas cognitivas, es decir, aquellas mediante las cuales se genera, se aplica y se evalúan diferentes formas de conocimiento. Nos alejamos pues de una concepción de la epistemología como la disciplina filosófica que busca explicitar los primeros principios del conocimiento y explicar porqué son fundamentales, es decir, porqué actúan como fundamentos de todo conocimiento, pues consideramos que un proyecto así es imposible porque no existen tales principios básicos si se consideran inmutables, absolutos y trascendentes a los paradigmas cognoscitivos y a las prácticas sociales humanas.

Tanto la epistemología como la ética tienen entonces una dimensión descriptiva y una dimensión normativa. Se encargan por una parte del análisis de ciertas prácticas sociales tal y como éstas existen y se han desarrollado de hecho, pero dicho análisis debe ser crítico y conducir al establecimiento de normas más adecuadas para ciertos fines. En el caso de la epistemología, su dimensión normativa debe llevarla a proponer reformas en la estructura axiológica de las prácticas, de modo que los valores y normas recomendados conduzcan a mejores procedimientos para la generación y acepta- 
ción de conocimientos adecuados para realizar determinados fines (por ejemplo la manipulación de fenómenos y la predicción exitosa en ciertos campos, o la comprensión de significados de acciones humanas en otros, o la resolución de ciertos problemas); en el caso de la ética lo que se buscaría sería el establecimiento de normas y valores para la convivencia armoniosa, pacífica y cooperativa entre grupos con diferentes morales y con diferentes intereses y visiones del mundo.

En el caso de la bioética se buscaría el establecimiento de normas y valores que permitan el desarrollo de prácticas -que sean éticamente aceptables-pertinentes para el fenómeno de la vida en todos sus aspectos, desde la salud y el bienestar de los seres humanos y el reconocimiento y respeto de los derechos de los animales, hasta la conservación sustentable del ambiente.

Defendemos, en suma, una perspectiva en la línea de un "normativismo naturalizado", por ejemplo como fue sugerido por Larry Laudan (1987). Esta concepción rechaza la idea de que las normas, sean epistémicas o éticas, tengan un carácter a priori, universal y absoluto. Las normas se conciben, desde el punto de vista que queremos defender, como teniendo un carácter a priori, en la medida en que son condiciones de posibilidad de juicios de valor (epistémico o ético), pero el sentido de a priori aquí asumido incluye la idea de que las normas cambian y tienen un desarrollo histórico, se trata pues de un a priori relativo e histórico.

Pero la posición sigue siendo "normativista" porque no deja de lado la tarea prescriptiva de la epistemología o de la ética. Sin embargo se entiende que las normas surgen en el seno de las prácticas sociales humanas y no tienen una fundamentación trascendente a ellas. Por otro lado, este punto de vista es un normativismo "naturalizado" porque parte de la idea de que la fuerza normativa de la estructura axiológica en cuestión, sea epistémica o ética, debe entenderse dentro de los contextos históricos en donde la aplicación de esas normas y de esos valores han conducido a decisiones exitosas por parte de los miembros de las prácticas pertinentes reales, y que para comprenderlas y mejorarlas es necesario partir de un análisis empírico de esas estructuras normativas. 


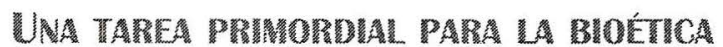

De acuerdo con las ideas expuestas hasta aquí, una de las tareas centrales para la bioética es el análisis crítico y propositivo de la estructura axiológica de las prácticas biomédicas y en general de todas las prácticas sociales relevantes para el fenómeno de la vida en el planeta. Es decir, a partir de un conocimiento factual de las prácticas pertinentes, la bioética debe revisar constantemente las normas y valores constitutivos de ellas para proponer y defender auténticas normas y valores bio-éticos (en el sentido de "ética" antes señalado).

¿Cuál es el estatus de las normas éticas y de las normas bioéticas? Se trata de normas que no suponen una fundamentación en principios absolutos a priori, ni se supone que sean aceptables con base en razones universales (es decir, razones que serían tales para todo sujeto racional posible), sino que aspiran a la aceptabilidad por parte de diferentes grupos sociales, con diferentes morales positivas, aunque por diferentes razones. Se trata entonces de normas que se llevan a "la mesa de negociación", con pretensión de aceptabilidad racional, pero sin suponer que eso significa que existe un único conjunto de razones universales para aceptar o rechazar la pretendida norma, sino que una norma será universalmente aceptable si realmente los diferentes grupos sociales para quienes resultará pertinente encuentran razones (sus propias razones) para aceptarla.

El caso de la legislación que debería prevalecer en relación con el aborto en un Estado laico puede ilustrar este planteamiento. Puesto que un Estado laico no debe comprometerse con ningún punto de vista religioso ni moral particular en torno a la admisibilidad o condena del aborto, el Estado y los ciudadanos deben llegar a un acuerdo acerca de las normas que regularán las decisiones y acciones del Estado al respecto. Tales normas deberían permitir que los ciudadanos actúen de acuerdo con sus particulares principios y valores morales, pero no deberían por ejemplo obligar al Estado a imponer un castigo a las mujeres, o a las parejas, que decidan 
un aborto, pues la condena del aborto depende de valores y principios morales específicos que varían de un grupo social a otro. La legislación del Estado laico entonces debería basarse en una norma ética que no obligue a castigar a quienes no creen que el aborto sea moralmente condenable. Dicha norma debería ser aceptable para todos los ciudadanos -incluyendo aquellos que condenan moralmente el aborto- en aras de una actitud ética tolerante con otros puntos de vista morales, con el fin de lograr una convivencia armoniosa entre diversos grupos sociales, religiosos o étnicos.

Como un ejemplo veamos cómo esta perspectiva permite fundamentar una tesis ética en cuestiones de riesgo y bioseguridad, la cual a la vez tiene consecuencias sobre legislación y políticas públicas.

En las modernas sociedades democráticas, para todo tipo de riesgo que afecte los intereses de un sector de la sociedad, o que afecte a la naturaleza, como es el caso de muchas tecnologías que plantean algunos de los principales retos a la bioética, es indispensable la participación pública en el proceso que va de la identificación a la gestión del riesgo.

Si esta tesis es correcta, serviría por ejemplo para fundamentar la obligación de un Estado o de un organismo internacional, en materia de legislación sobre bioseguridad, de establecer mecanismos de vigilancia y control de riesgos, por ejemplo en relación con aplicaciones biotecnológicas (digamos liberación de organismos genéticamente modificados al ambiente) en donde participen junto con expertos de diferentes disciplinas, representantes de diversos sectores sociales, aunque no sean considerados expertos en un sentido convencional.

La fundamentación de esta tesis ética tiene un inevitable contenido epistemológico porque no hay una única manera correcta de identificar los riesgos. Por razones epistemológicas tampoco hay una sola estimación acertada, ni una única valoración justa, y por lo tanto tampoco es posible una sola gestión del riesgo que sea la única correcta y éticamente aceptable. Sobre todo esto puede haber diferentes puntos de vista tan legítimos unos como otros. 
De lo anterior, junto con los supuestos bien atrincherados del pensamiento moderno que dicen que las personas son racionales y autónomas, se deriva la justificación ética de la participación pública en la identificación, evaluación y gestión del riesgo. Una consecuencia de esta posición será la defensa del ideal de una democracia participativa con fundamentos éticos, que podría superar algunos vicios que se han dado en las democracias formales realmente existentes, como el crecimiento descontrolado de armas (por ejemplo bacteriológicas) con pleno desconocimiento de los ciudadanos.

\section{CONSECUENCIAS PARA LA IDEA DEL TRÁNSTTO A LA SOCIEDAD DEL CONOCMMENTE}

¿Qué conclusiones podemos obtener para los países iberoamericanos si han de fortalecer sus culturas científicas, tecnológicas y científico-tecnológicas para aprovechar mejor los beneficios de la ciencia y la tecnología, pero al mismo tiempo para vigilar y encauzar sus efectos en la sociedad, en la cultura y en el ambiente? Esto es fundamental si nuestros países han de transitar hacia una sociedad del conocimiento, cada uno íntegramente, como país en su conjunto, y no sólo en beneficio de ciertas minorías privilegiadas.

Lo primero es que sería un grave error creer que el tránsito a una sociedad del conocimiento dependerá simplemente de "aprender a usar" determinados artefactos producidos por sistemas tecnocientíficos de otros países (como los ordenadores, las redes telemáticas o los organismos genéticamente modificados). Se trata más bien de tener la capacidad de generar mayor conocimiento (científico, tecnológico y tecnocientífico), pero en un marco de relaciones sociales y culturales adecuadas para su aprovechamiento. El problema central poder generar y aprovechar los sistemas científicos, técnicos, tecnológicos y tecnocientíficos que sean apropiados para resolver los problemas tal y como los definan los diferentes grupos humanos. Pero esas definiciones variarán según la cultura de cada grupo. 
La ciencia, la tecnología y la tecnociencia son hoy en día herramientas indispensables para el desarrollo económico, educativo y cultural de los pueblos, y de su fortalecimiento y aprovechamiento depende en gran medida el tránsito a la sociedad del conocimiento. Para ello es necesario fortalecer los canales de comunicación entre los sistemas científicos, tecnológicos y tecnocientíficos y el resto de la sociedad, impulsar la educación en ciencia y tecnología, y realizar cambios en las instituciones, en la legislación y en las políticas públicas. Pero también es indispensable desarrollar la cultura científica, tecnológica y científico-tecnológica de una manera adecuada en el contexto de sociedades culturalmente diversas.

Esto significa que la meta a lograr no es sólo que la gente entienda el contenido de las teorías científicas, o que se entere de los hallazgos tecnocientíficos (que tal gen es responsable de la enfermedad $\mathrm{x}$ y que por tanto se ha avanzado en la posibilidad de crear un fármaco ad hoc para esa enfermedad), sino que el objetivo debe ser desarrollar la cultura tecnológica, tanto la no incorporada como la incorporada a sistemas tecnológicos específicos -aquéllos que después de una evaluación desde la perspectiva de la cultura tecnológica no incorporada, sean aprobados por quienes serán sus operarios, sus usuarios y los afectados por dicha tecnología.

El problema central al pensar en las políticas educativas, así como en las de ciencia y tecnología que se requieren, es no olvidar cuál debe ser la unidad de análisis fundamental: si se piensa en ciencia no debe caerse en el error de creer que la ciencia se reduce al conocimiento científico; si se piensa en tecnología no debe caerse en el error de creer que la tecnología se reduce a las técnicas y a los artefactos, olvidando a los agentes que diseñan, operan y evalúan a los sistemas tecnológicos, así como al resto de los agentes que pueden ser afectados en sus vidas y en su cultura, en sus diferentes prácticas, por esos sistemas, y quienes por tanto también deben hacer una evaluación y tienen todo el derecho para incidir en el desarrollo y aplicación de un sistema tecnológico específico y en la vigilancia y control de sus consecuencias. La unidad de análisis debe incluir a los sistemas tecnológicos y tecnocientíficos con su 
dimensión de cultura incorporada, y deben considerarse los puntos de vista desde la cultura no incorporada.

Los sistemas técnicos, tecnológicos y tecnocientíficos afectan a la cultura impactando prácticas sociales específicas. Al analizar el impacto cultural de la tecnología se debe considerar a los agentes intencionales, los seres humanos de carne y hueso que constituyen la médula de los sistemas tecnológicos y científicos, así como las prácticas sociales que son transformadas como consecuencia de la operación de esos sistemas, es decir, debe analizarse la manera en la que los agentes se ven inducidos y a veces obligados a hacer las cosas de otro modo. Por ejemplo, a cambiar sus prácticas de cultivo, cuando por determinadas características de las semillas genéticamente modificadas éstas ya no pueden ser guardadas y utilizadas en la siguiente siembra como suelen hacer los agricultores tradicionales. Por consiguiente las políticas pertinentes deben tener como objetivo fomentar las transformaciones adecuadas en esas prácticas, para fortalecer los rasgos culturales correspondientes, y no pensar en abstracto en el desarrollo del conocimiento o de la tecnología.

El desafio para el fortalecimiento de una cultura tecnológica y de un adecuado tránsito a una sociedad del conocimiento es que los miembros de diversos grupos, en función de sus fines y de sus valores, pueda ejercer sus capacidades para generar y para apropiarse y aprovechar el conocimiento, tanto de los saberes tradicionales como de los científicos y los tecnocientíficos, pero sobre todo que pueda generar el conocimiento que mejor les sirva para alcanzar sus fines, manteniendo siempre la capacidad de decidir de manera autónoma cuáles son las prácticas que desean modificar, y en su caso en qué sentido aceptan cambiarlas, y cuáles no quieren alterar.

\section{LOS SISTEMAS SOCHALS CIENTIFCO-TECNOLÓGICOS}

Esto significa construir y fortalecer los que bien podríamos llamar sistemas sociales científico-tecnológicos. Tales sistemas incluyen a las comunidades de expertos de diferente clase -representantes de las ciencias naturales y exactas, así como de las sociales, de las huma- 
nidades y de las disciplinas tecnológicas-, a gestores profesionales de tales sistemas (profesión que aún no se ha desarrollado en Iberoamérica al nivel que se necesita actualmente), entre cuyas tareas se encuentra la atracción de fondos de inversión y su administración eficiente, profesionales de mediación que no sean sólo "divulgadores" del conocimiento científico, tecnológico y científico-tecnológico (que lleven mensajes sólo en el sentido de la tecnología y la tecnociencia a la sociedad), sino que sean capaces de comprender y articular las demandas de diferentes sectores sociales (empresarios, entre otros, pero no exclusivamente ellos, sino también otros gxupos sociales) y llevarlas hacia el medio científico-tecnológico y facilitar la comunicación entre unos y otros.

Los sistemas sociales científico-tecnológicos, que entendidos de esta manera serían un tipo de los llamados sistemas de innovación, incluyen entonces a los sistemas y procesos donde se genera el conocimiento, pero también a los mecanismos que garantizan que tal conocimiento será aprovechado socialmente para satisfacer demandas de diferentes sectores, y por medios aceptables desde el punto de vista de quienes serán afectados. Por eso es indispensable la participación de científicos sociales y de humanistas en esos sistemas. Pero como al final de cuentas tales sistemas deben tener como consecuencia beneficios para diferentes grupos sociales, es necesario que haya una participación de representantes de los grupos que serán afectados y, en su caso, beneficiados.

El fortalecimiento de tales sistemas implica el avance de la tecnología y la tecnociencia mediante un incremento de la inversión en ella, pero al desarrollarse mediante sistemas donde se da una comunicación entre los tecnólogos y tecnocientíficos expertos con quienes toman las decisiones concernientes a la inversión y quienes demandan el conocimiento para resolver sus problemas, el resultado es la consolidación de una auténtica cultura tecnológica y científico-tecnológica. Esto significa sobre todo que los ciudadanos y quienes toman las decisiones en los gobiernos y en el sector productivo aprecian el valor de la ciencia y la tecnología, y junto con los expertos entienden que la tecnología y la tecnociencia tienen un 
enorme potencial para coadyuvar al desarrollo económico y social y a la comprensión y resolución de problemas, saben por qué es razonable confiar en esos sistemas y cuáles son sus límites, saben también que generan riesgos pero que existen maneras ética, económica y políticamente aceptables de contender con ellos mediante mecanismos en donde participen expertos y representantes de los grupos sociales involucrados, y saben también la conveniencia de aprovechar otros saberes, como los tradicionales.

La construcción de una auténtica cultura técnica, tecnológica y científico-tecnológica, por tanto, requiere un gran esfuerzo educativo desde la escuela primaria hasta el nivel universitario y de postgrado, sin olvidar todo el campo de la educación no formal, y va de la mano de la construcción y fortalecimiento de los sistemas sociales científico-tecnológicos, con el fin de modificar las actitudes básicas de los agentes sobre los sistemas tecnológicos. Esto requiere profundas transformaciones institucionales, legislativas y estructurales en el Estado y en las actitudes de todos los ciudadanos. La tarea es titánica, pero si no respondemos adecuadamente a este desafío, la sociedad del conocimiento en nuestros países latinoamericanos no será sino una etiqueta vacía más. 


\section{BIBUMOCRATIA}

BUNGE, Mario. Ética, ciencia y técnica. Buenos Aires: Sudamericana, 1996.

CASTELLS, Manuel. La era de la información: Economía, sociedad y cultura, vol. 1, La sociedad red. México: Siglo XXI, 1999.

ECHEVERRÍA, Javier. Ciencia y valores. Barcelona: Destino, 2002.

La revolución tecnocientífica. Madrid: Fondo de Cultura Económica, 2003.

HUTCHINS, Edwin. Cognition in the Wild. Cambridge, Mass.: Bradford Books, MIT Press, 1996.

LAUDAN, Larry. "Progress or Rationality? The prospects for Normative Naturalism". En: American Philosophical Quarterly, Volume 24, Number 1, January 1987, pp. 19-31.

MERTON, Robert K. 1942, "The normative structure of science" (publicado originalmente como "Science and Technology in a Democratic Order"). En: Merton 1973, (TSS), The Sociology of Science, Theoretical and Empirical Investigations. Edited by Norman W. Storer, Chicago y Londres: The University of Chicago Press, pp. 267-278.

MOSTERÍN, Jesús. Filosofia de la cultura. Madrid: Alianza, 1993.

OLIVÉ, León. Interculturalismo y justicia social. México: Paidós, 2004.

QUINTANILLA, Miguel Ángel. Tecnología, un ensayo filosóficos y otros ensayos sobre filosofia de la tecnología. México, Fondo de Cultura Económica, 2005.

y AIBAR, Eduardo. Cultura tecnológica. Estudios de ciencia, tecnología y sociedad. Barcelona: Horsori, 2002.

SCHATZKI, Theodore R. Social Practices, A Wittgensteinian Approach to Human Activity and the Social. Cambridge: Cambridge University Press, 1996.

; KNORR, Cetina K. y E. Savigny (eds.). The Practice Turn in Contemporary Theory. Londres y Nueva Cork: Routledge, 2001.

SOBREVILIAA, David. Filosofía de la Cultura, vol. 15 de la Enciclopedia Iberoamericana de Filosofia. Madrid: Trotta-CSIC, 1998. 
